\title{
Allelic losses and gains during translocations of a high conservation value fish, Coregonus lavaretus
}

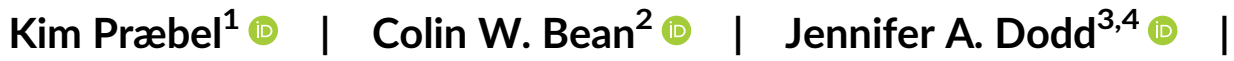 \\ Elizabeth C. Etheridge $^{5}$ | Andrew R.D. Gowans ${ }^{6}$ | Rune Knudsen ${ }^{7}$ R I । $^{\circ}$ \\ Alexander A. Lyle $^{3}$ | Peter S. Maitland ${ }^{3}$ | lan J. Winfield ${ }^{8}$ (i) | Colin E. Adams ${ }^{3}$
}

${ }^{1}$ Norwegian College of Fishery Science, UiT The Arctic University of Norway, Tromsø, Norway

${ }^{2}$ Scottish Natural Heritage, Glasgow, UK ${ }^{3}$ Scottish Centre for Ecology and the Natural Environment, University of Glasgow, Glasgow, UK

${ }^{4}$ Animal and Plant Sciences Group, Edinburgh Napier University, Edinburgh, UK

${ }^{5}$ Environment Agency, Reading, UK

${ }^{6}$ Environment Agency, Penrith, UK

${ }^{7}$ Department of Arctic and Marine Biology, UiT The Arctic University of Norway, Troms $\varnothing$, Norway

${ }^{8}$ Lake Ecosystems Group, UK Centre for Ecology and Hydrology, Lancaster, UK

\section{Correspondence}

Colin Adams, Scottish Centre for Ecology and the Natural Environment, University of Glasgow, Rowardennan, Glasgow G63 OAW, UK.

Email: colin.adams@glasgow.ac.uk

Funding information

UiT The Arctic University of Norway

\section{Abstract}

1. The use of translocations to establish new or 'refuge' populations for species with high conservation value is controversial but widely used in conservation management. One of the risks of this approach is that an establishing population does not adequately capture the genetic diversity of the donor gene pool. This effect, rarely examined, is tested here.

2. In this study the genetic consequences of two conservation translocations after five generations (16 years) of the European whitefish, Coregonus lavaretus, were quantified. Both translocations were made using almost the same genetic groups and thus represent a partly replicated natural study.

3. Analysis of 12 informative microsatellites showed that expected heterozygosity, the mean number of alleles per locus and allelic richness did not differ between donor and translocated populations. There was also no loss of heterozygosity in the translocated populations, nor deviations from Hardy-Weinberg equilibrium expectations, nor signs of linkage disequilibrium.

4. All populations were genetically differentiated but pairwise $F_{\mathrm{ST}}$ values were low, indicating that the magnitude of divergence was small.

5. There was no evidence of inbreeding but there were significant differences in private allelic richness between donor and translocated populations. Of 50 alleles found in the donor population, $16 \%$ of the rarer alleles were lost in one translocated population and $8 \%$ in the other.

6. Allele loss without a reduction in heterozygosity strongly points to stochastic drift effects having occurred following translocation. The evidence indicates that alleles that were not detected in the donor population have arisen de novo in the translocated populations.

7. It is concluded that conservation translocations comprising even a modest number of propagules can successfully capture a high proportion of genetic variation of the host population, and that reduced genetic variation in the

This is an open access article under the terms of the Creative Commons Attribution-NonCommercial License, which permits use, distribution and reproduction in any 
translocated population may be mitigated by the emergence of new variation over short time periods.

\section{KEYWORDS}

drift, genetic response, inbreeding, population genetics, wildlife management

\section{1 | INTRODUCTION}

The intentional movement and release of organisms to the wild at a site outside their natural range as a conservation tool to establish a new population of a species important for conservation, often termed a conservation translocation (sensu Griffith et al., 1986), is highly controversial (Ricciardi \& Simberloff, 2009; Müller \& Eriksson, 2013). Despite this, the immediate and pressing needs of conservation agencies and wildlife managers for pragmatic management tools to mitigate biodiversity loss have resulted in the widespread use of such techniques for a wide range of taxa (Linklater et al., 2011; Müller \& Eriksson, 2013; Thrimawithana et al., 2013).

Where enhancement of an existing population of high conservation value is considered, the goal is usually to promote gene flow between discrete or isolated populations occupying fragmented habitats. The ultimate aim is thus to maintain genetic variation in the recipient population by preventing the loss of genetic diversity by genetic drift or bottlenecking or through inbreeding depression (Storfer, 1999). The risk of this strategy for population enhancement is that, if successful, a flow of genes may constrain the speed and direction of local adaptation, a common feature of species that use fragmented habitats (Van Andel, 1998; Stockwell, Hendry \& Kinnison, 2003; Salminen et al., 2012). This might occur by simple swamping of the gene pool with maladapted genes - a situation that would be more likely if the population receiving the translocation was small and the number of translocated individuals relatively large. Alternatively, outbreeding depression could result in a reduction in fitness of offspring from the hybridization of translocated individuals with those of native origin (see review in Hufford \& Mazer, 2003). This risk increases with the degree of genetic divergence between the translocated individuals and the recipient population.

Where the establishment of a conservation refuge (elsewhere the equivalent terms 'safeguard' or 'ark' populations are used) outside the native range of a species is considered, the risks magnify. The dangers of moving species outside their native range to establish new populations may be significant, but they are generally well understood theoretically, and supported by a considerable weight of empirical evidence. These risks include causing significant perturbations to the recipient ecosystem through competitive, predatory and parasitic interactions as well as the introduction of new diseases or parasites (Ricciardi \& Simberloff, 2009). The risk of impact from deliberate translocations, even for laudable conservation goals, carries the same risks to the ecosystem. Our current, relatively poor, understanding of community ecology and invasion dynamics means that prediction of the impact of any specific translocation remains relatively limited (Ricciardi \& Simberloff, 2009).

In addition to the impact on the recipient ecosystem, there are also significant risks to the establishing population of the translocated species of conservation value. The most obvious is that translocation efforts will fail to establish a new population. Translocations generally have a low success rate (Chauvenet et al., 2013). If translocated populations do establish successfully, then there are several additional genetic risks that have the capacity to compromise the ultimate success of the conservation measure.

Founder effects: if the individuals that are translocated do not encapsulate the full diversity of the donor population gene pool, then the resultant establishing translocated population may not fully represent the genetic diversity of the donor population targeted for action. This means that although a conservation refuge population may become established, it may fail to represent adequately the donor population. This effect is more likely to occur if the translocated group comprises a small number of individuals, if they are closely related, or potentially if they are drawn from a limited geographical area (Stockwell, Mulvey \& Vinyard, 1996).

Genetic drift: similarly, a small number of translocated individuals drawn from a restricted genetic group of the donor population is more likely to be subject to the stochastic effects of genetic drift following establishment in the conservation refuge.

In-breeding depression: Even if the translocated group size is large but there is a high degree of relatedness within that group, then reduced fitness in subsequent generations as a result of in-breeding depression is possible (Hufford \& Mazer, 2003; Stockwell, Hendry \& Kinnison 2003).

Despite being widespread throughout northern Europe, the European whitefish, Coregonus lavaretus (L.) (hereafter 'whitefish'), is considered rare in the British Isles, where it is only naturally extant in seven locations (Winfield et al., 2013), only two of which are in Scotland (Loch Lomond and Loch Eck; Etheridge et al., 2012, and references therein). The species is strictly protected through national conservation legislation and it is a priority species in the UK Biodiversity Action Plan published by the Joint Nature Conservation Committee (JNCC, 2007). At an international level, whitefish are included in Annex $\mathrm{V}$ of the European Union Habitats Directive requiring member states to limit exploitation to ensure 'favourable conservation status' (Council of the European Communities, 1992) and the species' global status is identified as 'Vulnerable' in the International Union for the Conservation of Nature Red List 
(IUCN, 2015). Whitefish in the British Isles are therefore a conservation priority, and this has led to the development of a conservation programme to protect existing sites and to establish new refuge populations.

In 1982, a non-native fish species, the ruffe (Gymnocephalus cernuus), was discovered in one of the two sites supporting whitefish in Scotland, Loch Lomond (Maitland, East \& Morris, 1983). The population expanded rapidly over the following decade (Adams \& Maitland, 1998). Ruffe was shown to be preying heavily upon the eggs of whitefish and because of this, was identified as a significant threat to the whitefish population (Adams \& Tippett, 1991; Etheridge, Bean \& Adams, 2011). Consequently, action was undertaken to establish conservation refuge populations for this valuable whitefish population.

Between 1988 and 1990, eggs were stripped from 22 ovulating whitefish females collected from the wild at spawning time from the mid and south basins of Loch Lomond (56 $07.3^{\prime} \mathrm{N} 004^{\circ} 37.7^{\prime} \mathrm{W}$ ). Egg batches comprising those from a single female were fertilized with milt from at least two males in vitro and the eggs incubated in the laboratory. The resultant ca. 25,300 fry (which were about to begin exogenous feeding) were released to two previously identified conservation refuge sites: ca. 13,100 to Carron Valley Reservoir ( $56^{\circ} 01.9^{\prime} \mathrm{N} 004^{\circ} 06.1^{\prime} \mathrm{W}$ ) and ca. 12,200 to a second reservoir site, Loch Sloy (56 $16.3^{\prime} \mathrm{N} 004^{\circ} 46.6^{\prime} \mathrm{W}$ ); both sites are located within the Loch Lomond catchment (Figure 1). In addition, 85 adult whitefish (sex ratio unknown) were also translocated from Loch Lomond to Loch Sloy (Maitland \& Lyle, 1991; Etheridge et al., 2010; Lyle, Stephen \& Adams, 2017). Thus a maximum of 44 families, of which 22 family pairs comprised half sibs, was translocated to Carron Valley Reservoir and to Loch Sloy with a maximum of 42 breeding pairs also translocated to Loch Sloy. Thus, Loch Sloy is likely to have received a significantly higher number of propagule families than Carron Valley Reservoir. Multiple subsequent surveys to examine the status of these translocated populations have shown that the whitefish populations have become well established at both sites (more detail in Maitland \& Lyle, 2013).

The study described here examined this relatively mature (16 years) and replicated conservation translocation of whitefish to new locations within the same catchment, with similar environmental conditions, but which are effectively isolated from each other, to empirically test for evidence of consequential genetic effects.

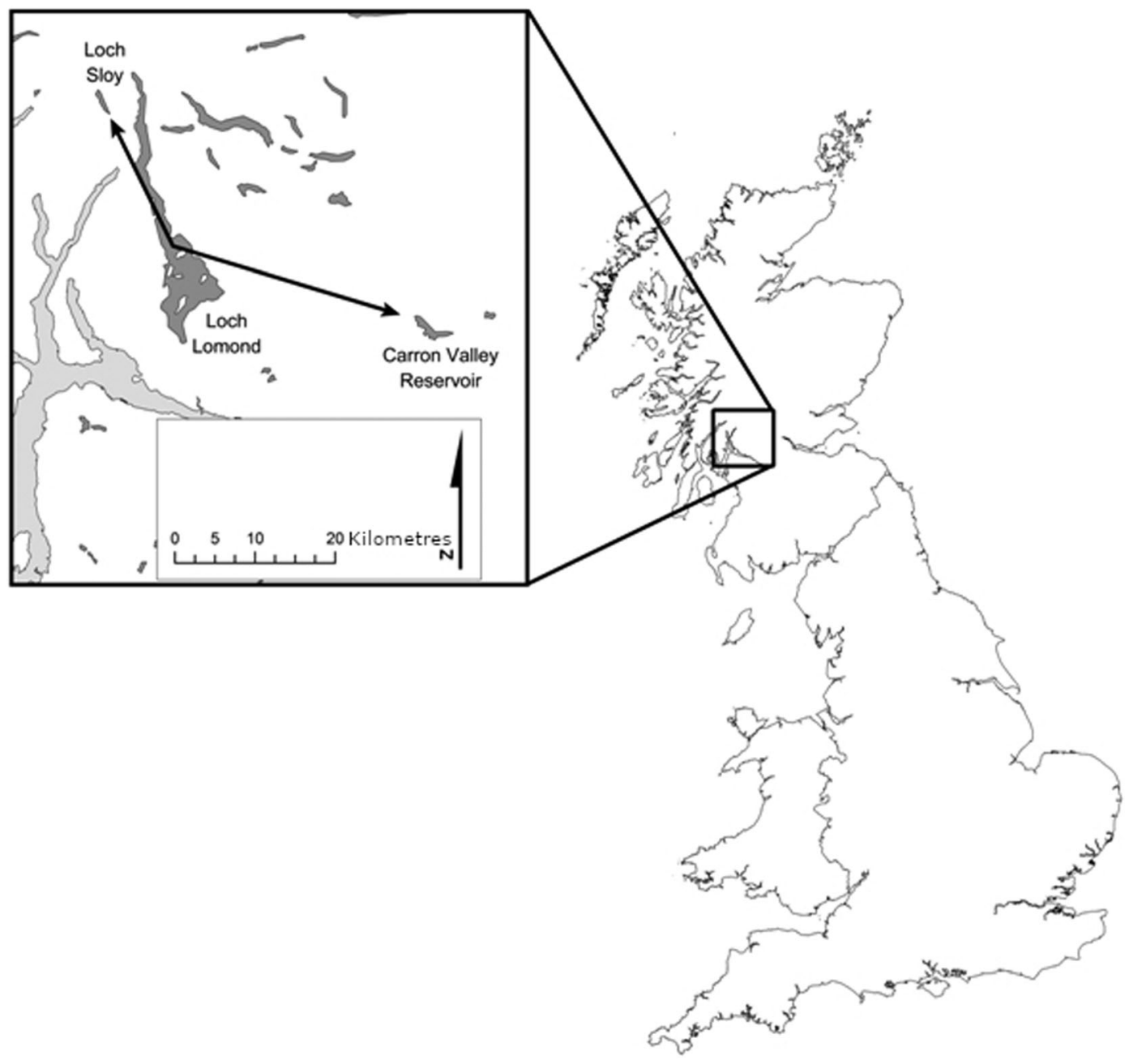

FIGURE 1 Map showing the locations of Loch Lomond (the donor site) and Loch Sloy and Carron Valley Reservoir (the translocation sites) 
The following hypotheses were specifically tested:

- there will be clear genetic differences between the gene pools of the translocated populations compared with that of the donor population;

- there will be reduced genetic diversity in the established, translocated populations;

- genetic drift has significantly modified the gene pool of the translocated populations; and

- inbreeding has modified the gene pools of the translocated populations.

\section{2 | METHODS}

Whitefish were collected for genetic analysis by gill net from the translocation donor site, (Loch Lomond) and from the two conservation refuge sites, (Loch Sloy and Carron Valley Reservoir) around the breeding season, November to January, between 2006 and 2009. Nordic-pattern gill nets comprising 12 panels, ranging from 5 to $55 \mathrm{~mm}$, knot-to-knot mesh were set overnight at sites in the south and mid basins of Loch Lomond (including the same sites from which fish were taken for the original translocation) and in Loch Sloy and Carron Valley Reservoir (Figure 1). An adipose fin clip was taken from each fish and stored in $100 \%$ ethanol.

Genomic DNA was extracted from adipose fin tissue using an E-Z96 Tissue DNA Kit (Omega Bio-Tek) following the manufacturer's instructions. In total, 15 microsatellite loci - BFRO-018 (Susnik, Snoj \& Dovc, 1999) BWF1, BWF2 (Patton et al., 1997), C2-157 (Turgeon, Estoup \& Bernatchez, 1999) Cla-Tet01, Cla-Tet03, Cla-Tet10, Cla-Tet13, Cla-Tet15, Cla-Tet18 (Winkler \& Weiss, 2008), Cocl-lav04, Cocl-lav06, Cocl-lav10, Cocl-lav18 and Cocl-lav49 (Rogers, Marchand \& Bernatchez, 2004) - were amplified using forward-labelled primers in four polymerase chain reaction (PCR) multiplexes following a published protocol (Præbel et al., 2013). The PCR products were separated on an ABI 3130 XL Automated Genetic Analyzer (Applied Biosystems; Massachusetts, USA) using Genescan LIZ-500 (Applied Biosystems; Massachusetts, USA) as an internal size standard. The binning and scoring were performed in Genemapper 3.7 (Applied Biosystems, Massachusets, USA) and manually verified. Replicate (5-9\%) and blind (4\%) samples were included in all PCRs to confirm consistency of scoring and absence of contamination. The repeatability and consistency of genotypes were $100 \%$. The samples were screened for abnormalities in the software Micro-Checker 2.2.3 (Van Oosterhout et al., 2004) using 1,000 bootstraps to generate the expected homozygote and heterozygote allele size difference frequencies.

Population-wide expected heterozygosity $\left(H_{\mathrm{e}}\right)$, Wrights inbreeding coefficient $F_{I S}$, departures from the Hardy-Weinberg equilibrium and linkage disequilibrium were tested by exact tests (Guo \& Thompson, 1992) as implemented in Genepop 4.0 (Rousset, 2007). The pair-wise comparisons were corrected for multiple comparisons using sequential Bonferroni corrections, following Rice, Schork \& Rao (2008). Standard genetic diversity measures - the number of alleles $\left(N_{A}\right)$ and expected $\left(H_{e}\right)$ and observed $\left(H_{0}\right)$ heterozygosity for each locus - for each population were estimated in GenAlEx (Peakall \& Smouse, 2006). To investigate whether the translocations have affected the mean $\mathrm{N}_{\mathrm{A}}$ and mean $\mathrm{H}_{\mathrm{e}}$ of the translocated populations, means were compared using a general linear mixed model (GLMM; including locus as a random effect) with a Poisson distribution and a linear model, respectively, in the R programming environment (R Core Team, 2017). Post hoc tests for the GLMM were undertaken using the multcomp package (Hothorn, Bretz \& Westfall, 2008) and Tukey Honest Significant Difference (HSD) test for the linear model.

The effects of translocation on the genetic diversity of the translocated populations were also addressed by estimating the allelic richness $\left(N_{\text {AR }}\right)$ and private allelic richness $\left(N_{\text {PAR }}\right)$ in HP-Rare (Kalinowski, 2005) using the smallest sample size from a single site (38 individuals) for rarefaction. The mean number of distinct alleles (analogous to allelic richness, $N_{\mathrm{ADR}}$ ) and the mean number of private distinct alleles per locus ( $N_{\text {PDAR }}$ ) in generalized sample sizes (two to 38 diploid individuals) and their associated standard errors were determined using ADZE (Szpiech, Jakobsson \& Rosenberg, 2008). ADZE uses a rarefaction approach (e.g. Kalinowski, 2005) to compute a measure of the generalized private allelic richness. ADZE thereby allows for estimates of the number of distinct alleles, private to a group of populations. This approach was also used to estimate the proportion of missing alleles in the translocated populations by assessing the mean number of private distinct alleles per locus ( $\left.N_{\text {MPDAR }}\right)$ in combinations of the donor and the translocated populations. The between-population number of alleles per locus and allelic richness were compared using GLMM. To gain further insight into the effect of the translocation process the mean number of private distinct alleles ( $N_{\text {PDAR-L }}$ ) and allele frequency distributions for each locus were examined separately. Between-population private allelic richness derived from ADZE was compared using a paired $t$-test (paired by locus).

Genetic differentiation between each of the populations was estimated by $F_{\mathrm{ST}}$ (equivalent to $\theta$; Weir \& Cockerham, 1984) and tested for significance by 10,000 permutations using Arlequin 3.5.1.2 (Excoffier \& Lischer, 2010).

To assess the possibility of a contribution of random genetic drift, the effective population sizes $\left(N_{e}\right)$ using OneSamp 1.1 (Tallmon et al., 2008) were also assessed. This software uses approximate Bayesian computation to estimate variance $N_{e}$ from summary statistics that are related to $N_{\mathrm{e}}$. Varying prior upper and lower bounds for $N_{e}$ of 2-150 to $10-1,000$ were tested in three replicate runs per prior. The prior bound that produced the most consistent $N_{e}$ estimate and the smallest $95 \%$ credible intervals was then chosen for all runs. The mean \pm SEM of 10 replicate estimates using prior upper and lower bounds for $\mathrm{Ne}_{\mathrm{e}}$ of $20-200$ are reported here. The neutrality of the loci used for the estimates was tested in BayesScan (Foll \& Gaggiotti, 2008) and DetSel (1.0) (Vitalis et al., 2003), which use Bayesian and coalescent approaches, respectively. The locus BWF2 was indicated as a potential outlier (balancing selection) at the $95 \%$ 
credible level in BayesScan but was not revealed as an outlier in DetSel. The locus was thus maintained in the dataset to ensure statistical power. There was no other evidence of loci used here being subject to selection. The sample size for each locus analysed is given in Table S1.

The study described here conformed fully with the UK Animals (Scientific Procedures) Act 1986.

\section{3 | RESULTS}

\subsection{Genotype validation and summary statistics}

Standard indices of within-population genetic variation for each locus are given in Table S1. Three loci (BFRO-018, Cocl-lav04 and Cocl-lav10) were monomorphic and omitted from further analysis. The mean $N_{\mathrm{A}}$ per locus for each lake varied from two to eight across the remaining 12 loci. The $H_{\mathrm{e}}$ and $H_{\mathrm{o}}$ per locus per lake varied from 0.000 to 0.777 and from 0.000 to 0.897 , respectively (Table S1). Deviations from Hardy-Weinberg equilibrium at individual loci, returned three out of 36 tests that were initially statistically significant $(P<0.05)$, but all statistical significance was lost after applying sequential Bonferroni corrections (Supplementary Table S1). Similarly, five out of 66 tests for linkage disequilibrium were initially significant $(P<0.05)$, but significance was lost after applying sequential Bonferroni corrections. The Micro-Checker analysis indicated no abnormality for any of the per locus tests. Thus, overall there was no evidence of deviations from Hardy-Weinberg expectations, signatures of linkage disequilibrium or any other abnormality for any locus in any of the three populations.

\section{2 | Genetic differences between translocated and donor populations}

The estimates of pair-wise genetic differentiation showed that the translocated populations are significantly discriminated from the donor population (Loch Lomond vs. Loch Sloy, $F_{\mathrm{ST}}=0.027, P<0.001$; Loch Lomond vs. Carron Valley, $\left.F_{\mathrm{ST}}=0.014, P<0.005\right)$. Notably, the $F_{\mathrm{ST}}$ calculated between the translocated populations exceeds that of the genetic differentiation between the donor and the translocated populations (Loch Sloy vs. Carron Valley, $F_{\mathrm{ST}}=0.061, P<0.001$ ), suggesting that stochastic effects of genetic change are operating.

\subsection{Translocation changes allele frequencies and favours accumulation of rare and private alleles}

A total of 54 alleles were identified among the 12 microsatellite loci assayed in samples from the three lakes. Fifty of these alleles were found in the donor population, Loch Lomond; 43 alleles were found in the population from Loch Sloy (of which 42 were also seen in fish from Loch Lomond) and 48 alleles were found in the population from Carron Valley Reservoir (of which 46 were also seen in Loch Lomond). A similar pattern was observed for the mean $N_{A}$. Loch Lomond had a higher mean number of alleles per locus $\left(N_{A}=4.3 \pm 0.6\right.$, mean \pm SEM) than both Loch Sloy $\left(N_{A}=3.6 \pm 0.5\right)$ and Carron Valley Reservoir $\left(N_{\mathrm{A}}=3.8 \pm 0.4\right)$ (Table 1). Similarly, Loch Lomond also displayed the highest allelic richness $\left(N_{A R}=4.2 \pm 0.6\right)$ compared with Loch Sloy $\left(N_{A R}=3.6 \pm 0.6\right)$ and Carron Valley Reservoir $\left(N_{A R}=3.7 \pm 0.4\right)$ (Table 1), although none of the differences were statistically significant $(P>0.05)$. Loch Lomond did have a significantly higher private allelic richness (Loch Lomond $N_{\text {PAR }}=0.5 \pm 0.1$ ) than Loch Sloy (Loch Sloy $N_{\text {PAR }}=0.1 \pm 0.1, P=0.03$ ), but this was similar to that of Carron Valley Reservoir (Carron Valley $N_{P A R}=0.3 \pm 0.1$, paired $t$-test, $P>0.05)$. The private allelic richness did not significantly differ between Loch Sloy and Carron Valley Reservoir $(P>0.05)$.

Unsurprisingly, the number of distinct alleles per locus increased with sample size (Figure 2a). Despite this, the number of alleles per locus did not differ significantly $(P>0.05)$ between fish from Loch Lomond and either Loch Sloy or Carron Valley Reservoir. Similarly, the mean number of private distinct alleles per locus increased with sample size but this was higher for fish from Loch Lomond compared with Loch Sloy $(P<0.03)$ and Carron Valley Reservoir $(P<0.05)$ (Figure $2 b)$. A pairwise comparison between the three sites showed that the mean number of missing private distinct alleles per locus was similar between fish from Loch Lomond and Carron Valley Reservoir and between Loch Lomond and Loch Sloy, but that distinct private alleles are missing between Carron Valley Reservoir and Loch Sloy (Figure 2c).

To reveal the patterns of allelic change related to the translocations, a closer examination was made of the allelic identity and frequency for three loci (BWF1, Cla-Tet03 and Cla-Tet18) where there was at least one allele present in the donor (Loch Lomond) population, but which was not detected in one or both of the translocated populations (Loch Sloy or Carron Valley Reservoir). Examination of these loci indicates that some of the alleles with low frequencies have been lost in the translocated populations of Loch Sloy and Carron Valley Reservoir (Figure 3a). Allele 221 at locus
TABLE 1 Summary of samples and the genetic indices reported in the study for the three lakes

\begin{tabular}{llllllll} 
Lake & $\mathbf{N}$ & $\boldsymbol{H}_{\mathrm{e}}$ & \multicolumn{1}{c}{$\boldsymbol{F}_{\mathrm{IS}}$} & $\boldsymbol{P}_{\mathrm{HWE}}$ & $\mathrm{N}_{\mathrm{A}}$ & $\mathrm{N}_{\text {AR }}$ & $N_{\mathrm{e}}$ \\
\hline Loch Lomond & 40 & 0.433 & -0.018 & N.S. & $4.3 \pm 0.6$ & $4.2 \pm 0.6$ & $46 \pm 1$ \\
\hline Loch Sloy & 39 & 0.394 & 0.015 & N.S & $3.6 \pm 0.5$ & $3.6 \pm 0.5$ & $40 \pm 1$ \\
\hline Carron Valley & 38 & 0.455 & -0.025 & N.S & $3.8 \pm 0.4$ & $3.7 \pm 0.4$ & $36 \pm 1$ \\
\hline
\end{tabular}

Note: Lakes sampled, sample size $(N)$, expected heterozygosity $\left(H_{\mathrm{e}}\right)$, the inbreeding coefficient $\left(F_{\mathrm{IS}}\right)$, the significance from the Hardy-Weinberg equilibrium test $\left(P_{\mathrm{HWE}}\right)$, mean number of alleles $\left(N_{\mathrm{A}} \pm \mathrm{SEM}\right)$, the allelic richness ( $N_{\mathrm{AR}} \pm \mathrm{SEM}, 38$ individuals) and the mean effective population size $\left(N_{\mathrm{e}}\right) \pm \mathrm{SEM}$ are shown for 10 replicated runs. 
(a)

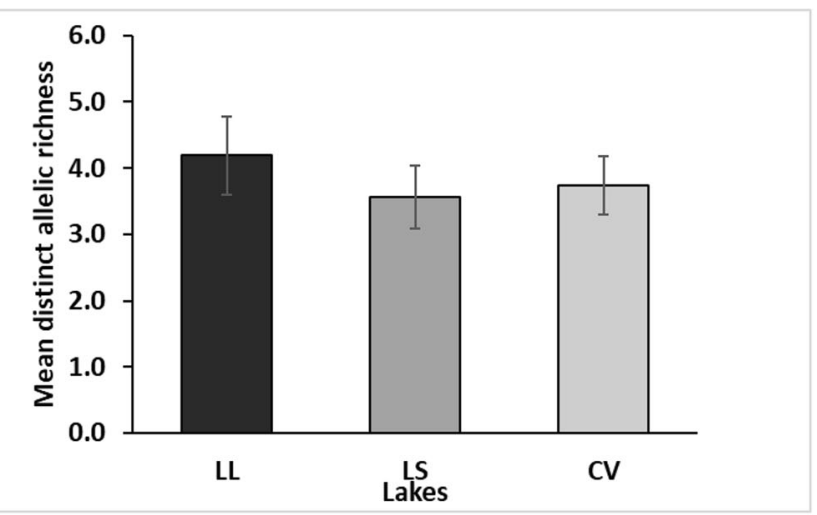

(b)

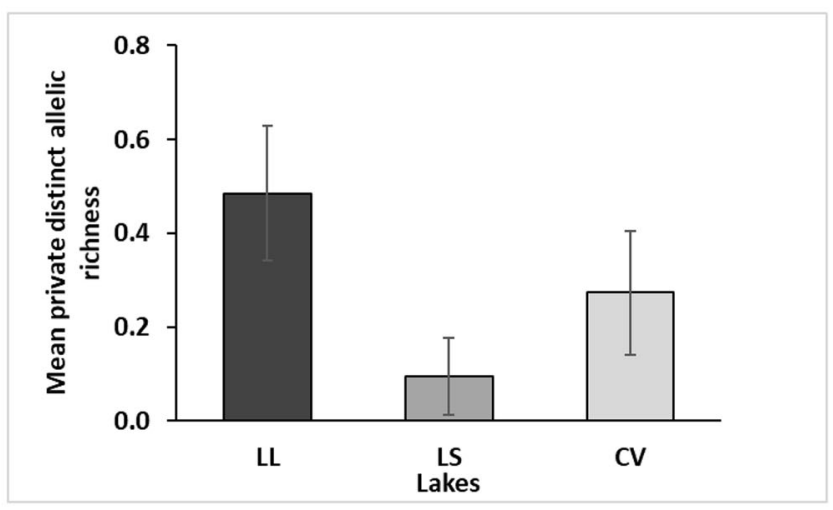

(c)

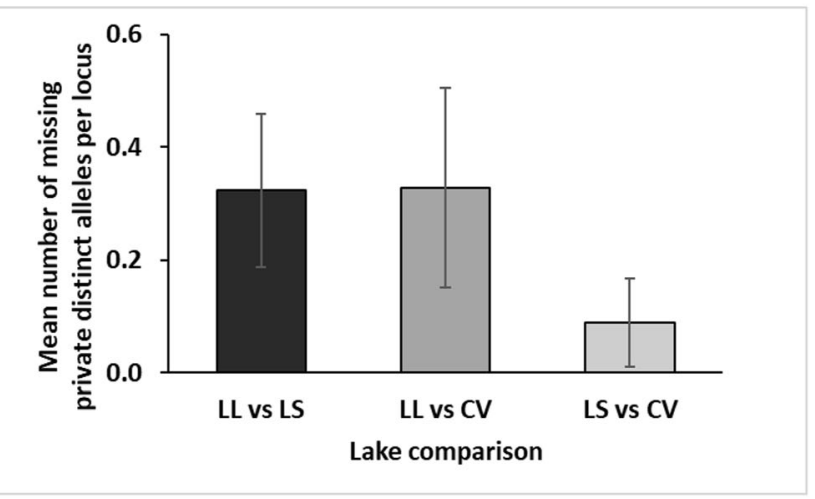

FIGURE 2 The mean number of distinct alleles (allelic richness) per locus (a), the mean number of private distinct alleles per locus (b), and the mean number of missing private distinct alleles per locus (c) in the donor lake (Loch Lomond, LL) and the two translocation sites (Loch Sloy [LS] and Carron Valley Reservoir [CV]) using standardized sample sizes of 38 diploid individuals from each site. Error bars denote standard error of the means

BWF1, allele 272 at locus Cla-Tet03 and allele 307 on locus Cla-Tet18 were all not detected in fish from either Carron Valley Reservoir or Loch Sloy (Figure 3a). When examining the loci Cla-Tet01, Cla-Tet13 and Cocl_lav49 in more detail, marked differences were also observed in the pattern of private alleles across the three populations. At Cla-Tet01, allele 178 was not detected in fish from the sample taken from Loch Sloy but it was detected in Loch Lomond and Carron Valley Reservoir. In addition, the translocated population in Carron Valley Reservoir had a high allelic frequency of the 190 allele at locus Cla-Tet01 compared with the Loch Lomond donor population for which allele 182 was the most common allele. At the Cla-Tet13 locus, allele 266 was not detected in fish from Loch Sloy but it was in fish from the other two sites. Allele 278 was detected at relatively high frequency at Carron Valley Reservoir, but it was not detected at the other two sites.

Analysis of the number of private alleles per locus suggests that sample size is not constraining the differences between sites (Figure 3 ) and strongly suggests that the accumulation of the new private allele in fish at Carron Valley Reservoir is the result of a private allele arising at this site. Similarly, fish from Carron Valley Reservoir returned a low frequency of allele 174 at locus Cocl_lav49, which was not detected at the other two sites. Loch Sloy fish also displayed allele 170, which was also not seen in fish collected from the other two sites. Analysis of the number of private alleles per locus with sample size indicates that sample size is not constraining the detection of these private alleles at the two translocation sites (Figure 3). Thus, the evidence presented here indicates that although alleles have been lost during the translocation process, new private alleles have also emerged in translocation sites.

\subsection{Stochastic contribution of genetic drift to the gene pools of the translocated populations}

The translocated populations (Loch Sloy $N_{\mathrm{e}}=40 \pm 1$; Caron Valley $N_{\mathrm{e}}=36 \pm 1$, mean \pm SEM) had significantly smaller effective population sizes than the donor population (Loch Lomond $N_{\mathrm{e}}=46 \pm 1$, mean $\pm \mathrm{SEM}$; Loch Lomond vs. Loch Sloy, $P=0.006$; Loch Lomond vs. Carron Valley Reservoir, $P<0.001)$. The $N_{e}$ of the two translocated populations also differed significantly $(P=0.011)$.

\section{5 | Signatures of inbreeding}

All populations showed high levels of heterozygosity, with Carron Valley Reservoir displaying the highest expected heterozygosity $\left(H_{\mathrm{e}}=0.455\right)$ of the three (Table 1$)$. With low $F_{\mathrm{IS}}$ indices for all populations there were no significant signatures of inbreeding (Table 1).

\section{4 | DISCUSSION}

The translocations of rare whitefish from the threatened population in Loch Lomond to two conservation refuge sites that were not connected to each other or to the donor population site, and thus technically outside its historically recorded native range in Scotland, both survived and established viable self-sustaining populations 
(a)
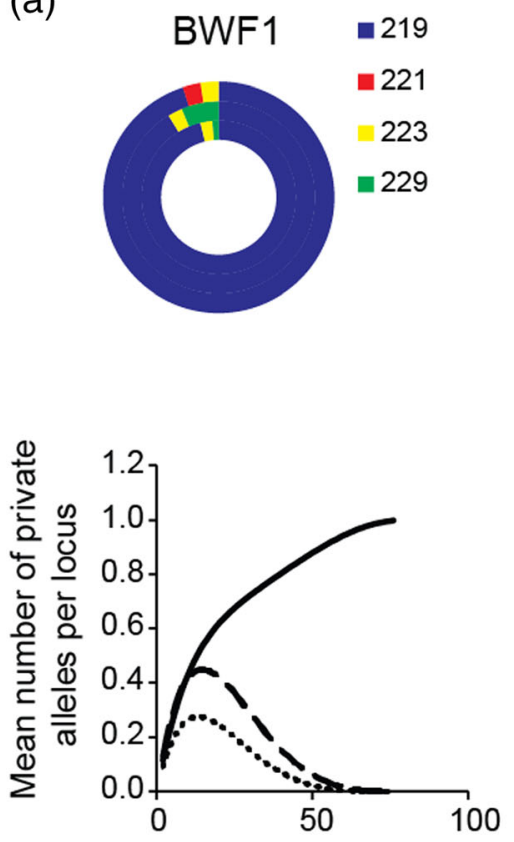

(b)
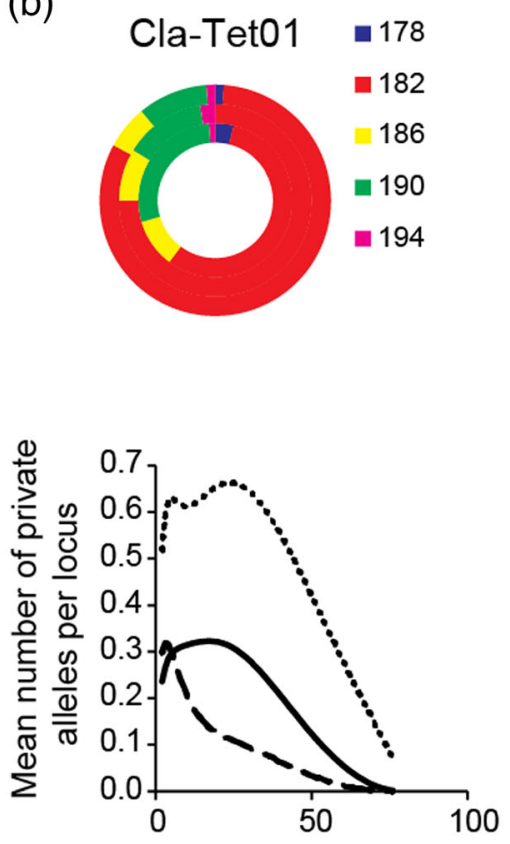
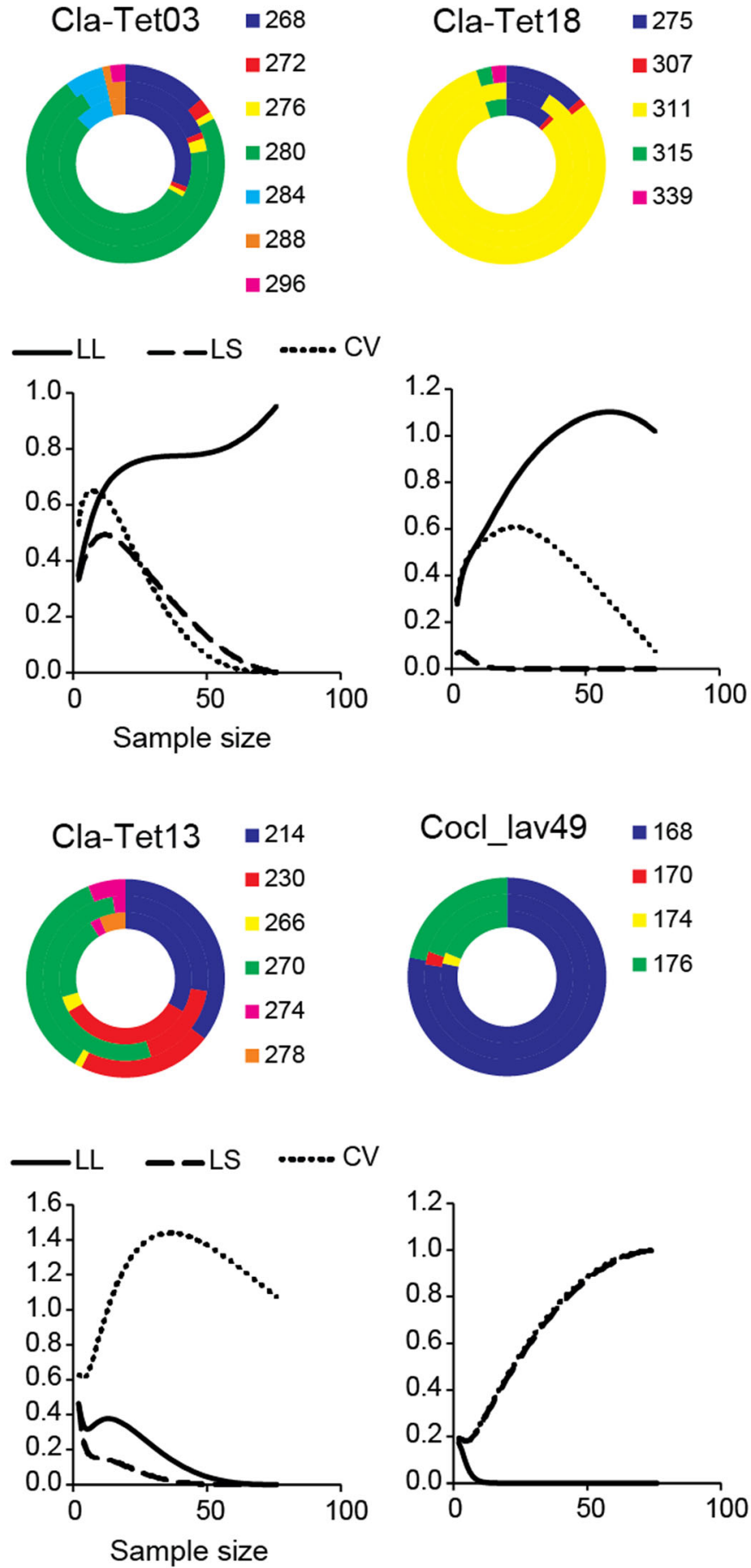

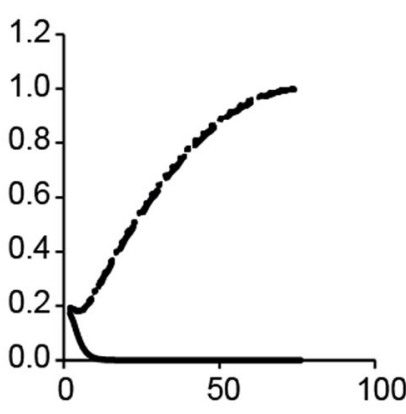

FIGURE 3 The effect of translocation at the locus level. Examples of allele frequencies and the associated estimates of private distinct alleles of loci in situations where alleles have not been translocated (a) and in situations where the allele frequencies have been greatly changed and/or new private alleles are accumulating (b). In the pie plots, Loch Lomond (LL), Loch Sloy (LS) and Carron Valley Reservoir (CV) are represented by the outer, mid and inner ring, respectively. The estimates of mean number of private distinct alleles of loci were made using standardized sample sizes from two to 38 diploid individuals

(Maitland \& Lyle, 2013; Adams et al., 2014). This contrasts with the generality that translocations made for whatever reason have a low rate of successful establishment (Chauvenet et al., 2013). These replicated translocation populations have sustained over at least 16 years and as whitefish in Scotland typically first become sexually mature at age 3 (Brown \& Scott, 1994) these populations have persisted over at least five generations. In the study presented here, there was a notable level of genetic similarity between the donor population and the replicated translocation populations. However, the differences that were manifest are informative. 
Conservation translocation is a tool that is relatively widely used in conservation management (Griffith et al., 1986; Linklater et al., 2011; Müller \& Eriksson, 2013; Thrimawithana et al., 2013), but there have been surprisingly few studies that have attempted to evaluate the consequences of this management practice on population genetics. In the study reported here the newly founded translocated populations showed subtle but detectable genetic differentiation from the donor population but there was no evidence of loss of heterozygosity, deviations from Hardy-Weinberg equilibrium expectations, inbreeding or signs of linkage disequilibrium. Although there was some loss of rarer alleles associated with the translocated populations suggesting that genetic drift had occurred, there was evidence of de novo emergence of novel alleles in the translocated populations.

As the foundation for this study, four potential genetic risks to the establishment of conservation refuges for whitefish were postulated. The first was that there would be detectable population genetic differences between the gene pools of the translocation populations compared with the donor population. This study has shown clear and statistically significant differences between whitefish from the donor population in Loch Lomond and both of the translocated populations. Analysis of 12 informative microsatellite loci across Loch Lomond (the donor population) and the two translocated populations (Carron Valley Reservoir and Loch Sloy) returned $F_{S T}$ values of 0.014 and 0.027 , respectively. Although these differences are detectable and statistically significant, they are relatively small. For example, the level of difference between donor and translocated populations reported here is similar to that reported between whitefish from the different localities within the donor lake, Loch Lomond $\left(F_{\mathrm{ST}}=0.001-0.024\right.$; see Adams et al., 2016). In contrast, the $F_{\mathrm{ST}}$ between the two native populations (Loch Lomond and Loch Eck) in Scotland that are isolated from each other and do not interbreed is 0.056 (Adams et al., 2016) and is comparable with $F_{\mathrm{ST}}$ values for recently diverged sympatric morphs of whitefish from Norway $\left(F_{\mathrm{ST}}\right.$ range from 0.04 to 0.1; Østbye et al., 2006; Siwertsson et al., 2013). The level of differentiation is also comparable with that observed in translocations of other coregonids (Coregonus albula L., $F_{\mathrm{ST}}=0.011$, after $\sim 12$ generations) and other groups: smelt (Osmerus eperlanus L., $F_{\mathrm{ST}}=0.011$, after $\sim 4$ generations); Arctic charr (Salvelinus alpinus L., $F_{\mathrm{ST}}=0.066$ after $\sim 20$ generations and $F_{\mathrm{ST}}=0.01-0.14$ after $\sim 25$ generations); and Arctic grayling (Thymallus thymallus L., $F_{\mathrm{ST}}=0.05-0.21, \sim 25$ generations, 80-120 years) (Koskinen, Haugen \& Primmer, 2002; Præbel et al., 2013; Hagenlund et al., 2015; Præbel et al., 2016; Hassve et al., 2020).

In one of the few studies to look for similar effects in other species, Wright et al. (2014) showed values of $F_{S T}$ ranging from 0.001 to 0.07 between donor and translocated populations of the passerine bird, the Seychelles warbler Acrocephalus sechellenis (Oustalet), that had become established for a maximum of 23 years.

Over a longer period of time and with some translocated populations being used to establish additional secondary translocations, Taylor \& Jamieson (2008) showed for the New Zealand saddleback Philesturnus carunculatus (Gmelin), another small passerine, that $F_{\mathrm{ST}}$ values ranged from 0.006 to 0.132 . The data from the study presented here strongly point to donor and translocated populations being genetically different, but the magnitude of this difference is relatively modest. Interestingly, the genetic difference between translocated populations $\left(F_{\mathrm{ST}}=0.06\right)$ was more than twice that observed between donor and translocated populations. This suggests that the mechanisms resulting in the divergence between donor and translocated populations are stochastic but that they are magnified between translocations.

A second prediction tested was that the conservation translocation did not capture the full genetic diversity of the donor population. Weeks et al. (2011) suggest that for a conservation translocation outside the natural range of the species being translocated (an 'introduction', sensu Weeks et al.) to be regarded as successful, it should capture greater than $95 \%$ of the standing genetic variation. This study was unable to detect significant differences in the mean number of alleles per locus or allelic richness between the donor and translocated populations. The donor population (Loch Lomond) did have a higher private allelic richness than one of the translocated populations (Loch Sloy) but not the other (Carron Valley Reservoir) and a higher number of distinct private alleles than both of the translocated populations.

Comparing the alleles identified in the donor population with those found at the two translocated populations, of the 50 alleles detected in Loch Lomond, eight (16\%) were not detected in the translocated population at Loch Sloy and four (8\%) were not detected at Carron Valley Reservoir. This suggests superficially that greater than $5 \%$ of the standing genetic variation was not captured in the translocation process to these two sites; however, there were no significant differences in the mean number of alleles per locus, allelic richness or heterozygosity between the donor and translocated populations. In their study on a conservation translocation of New Zealand saddlebacks, Taylor \& Jamieson (2008) concluded that translocation had not resulted in reduced diversity, on the basis that there was no significant difference between donor and translocated populations in the number of alleles, allelic richness and heterozygosity despite five alleles (out of 22) found in the donor population not being found in the translocated populations. Similarly, in their study on Seychelles warblers, Weeks et al. (2011) showed that, although a small number of rare alleles were lost and translocations produced subtle changes in gene frequencies, there was very little loss of neutral genetic diversity $(<5 \%)$ when the number of translocated individuals was approximately 30 pairs. An examination of the presence or absence of specific alleles in this study shows a very similar pattern, with the loss of a small number of alleles that were rare in the donor population but a non-significant loss of overall genetic diversity. This study focused only on selection-neutral genetic diversity; however, the study on Seychelles warblers also looked at functional genetic diversity and showed that a change in neutral diversity was a good proxy for changes in functional genes (Wright et al., 2014). It is thus reasonable to assume that the genetic change described in this study of selection-neutral markers is also likely to be reflected in functional genes. 
In the study presented here, it is surprising that both translocated populations exhibited alleles that were not found in the donor population. At the locus Cocl-lav49, fish from the translocated population at Carron Valley Reservoir contained an allele that was not found among Loch Lomond fish. Similarly, the translocated population from Loch Sloy exhibited a different allele at the same locus that was not seen in fish in either the donor or the other translocated population. At locus Cla-tet13, fish from Carron Valley Reservoir showed a high frequency of allele 278 that was not detected either in the donor population or in the other translocated population. In addition, allele 190 at locus Cla-tet01 was found at high frequency in the Carron Valley Reservoir population but only at low frequency in the donor population, the most common allele being 182 in Loch Lomond fish. In their study on New Zealand saddlebacks, Taylor \& Jamieson (2008) also recorded a small increase in the number of alleles in translocated populations compared with the donor population (an increase of three alleles in 22 recorded).

There are several possible explanations for this apparent increase in genetic diversity. It is possible that these alleles do exist in the Loch Lomond population but at a frequency that is low enough to prevent detection by the sample sizes used in this study, and that the population expansion in the donor populations allowed very rare alleles to become relatively more common. There are several strands of evidence that seem to make this explanation unlikely. The analysis of the effect of sample size on the number of private alleles indicates that the size of the sample is not constraining detection of private alleles at any of the three sites (Figure 3 ). In addition, the individual fish used to form the new translocated populations almost solely comprised a mixed genetic group of juveniles from multiple families that were randomly allocated to each translocation site (the exception to this being the few adult individuals that were translocated directly to Loch Sloy - see Methods and Maitland \& Lyle (2013) for details). As a consequence, any rare allele in these selection-neutral loci carried in fish from a family might be expected to be translocated and become numerous in both translocated populations simultaneously. This pattern was not observed; in fact, all private alleles that were novel to a translocated population were found in only one of the two populations, not in both. Lastly, this explanation for increased genetic diversity seems less likely given that the frequency of allele 278 at locus Cla_Tet13 was particularly high in fish at Carron Valley Reservoir and yet this allele was not detected in Loch Lomond (or Loch Sloy). At the very least the frequency of this allele must have significantly increased in the Carron Valley Reservoir population. An alternative explanation is that new private alleles have arisen de novo through mutation in situ in both of the translocated populations, creating novel genotypes. Although there is no way of definitively distinguishing between these two alternatives from the study presented here, this latter explanation is the more plausible.

The third prediction tested was that genetic drift has significantly modified the gene pool of translocated populations. In the translocated populations there is evidence of allele loss but no change in heterozygosity compared with the donor populations. In fact, one of the translocated populations (Carron Valley Reservoir) had the highest level of expected heterozygosity of the three populations, although for all populations expected heterozygosity was high. Allele loss, at a rate that is faster than heterozygosity loss, strongly points to the existence of genetic drift in the translocated populations. The significantly lower effective population sizes in the translocated populations compared with the donor population supports the conclusion that stochastic processes have resulted in the rarer alleles in the donor population being lost from the translocated populations. In contrast, studies on Seychelles warblers (Wright et al., 2014) concluded that genetic variation between donor and translocated populations was the result of genetic capture during the translocation process and not the result of subsequent genetic drift. Thus, genetic drift, although detectable, seems to have had relatively low impact on the gene pool of the replicated translocated populations of whitefish.

The fourth prediction tested is that inbreeding resulting from the relatively small population sizes created during the initial translocation process has had an effect on the translocated populations. In this study both translocated populations returned low levels of the inbreeding coefficient $F_{I S}$. This strongly points to there being no signature of any inbreeding in any of the three populations, and importantly after five generations in the translocated populations.

Altogether, there were detectable and statistically significant differences between the gene pools of the replicated translocated populations compared with that of the donor population, but these are relatively small. There were no clear signs of reduced genetic diversity in the established translocated populations. Furthermore, genetic drift and inbreeding seem to have a relatively low effect on the gene pool of the translocated populations. Thus, the general conclusion from this study is that even when the number of propagules transferred is relatively low, conservation translocations can capture a high proportion of the genetic variation found in the donor population. This is sufficient to avoid the adverse effects of inbreeding, heterozygosity loss and linkage disequilibrium that have the potential to impose significant impacts on the success of the conservation action. In addition, the potential negative effects of drift that may well be expected following translocation can be mitigated by the rapid emergence of novel genetic diversity. Fish species, with their high fecundity and thus an inherent high capacity for rapid population expansion, may have greater capacity for avoiding the potential deleterious effects associated with translocation. It remains to be tested if the outcomes of this study are reflected across taxa with lower inherent rates of population expansion.

\section{ACKNOWLEDGEMENTS}

We thank Wendylee Stott and Ellen George for perceptive comments on an early draft of this manuscript, Alastair Stephen and Scottish and Southern Energy for access to the Loch Sloy study site and Rowan Smith for technical support. Thanks to UiT the Arctic University of Norway for economical support of the study.

\section{CONFLICT OF INTEREST}

The authors have no conflict of interest to declare. 


\section{ORCID}

Kim Præbel (D) https://orcid.org/0000-0002-0681-1854

Colin W. Bean (D) https://orcid.org/0000-0003-3502-0995

Jennifer A. Dodd (iD https://orcid.org/0000-0002-0166-5720

Rune Knudsen (D) https://orcid.org/0000-0001-8579-4687

lan J. Winfield (D) https://orcid.org/0000-0001-9296-5114

Colin E. Adams (iD) https://orcid.org/0000-0003-2470-9754

\section{REFERENCES}

Adams, C.E., Bean, C.W., Dodd, J.A., Down, A., Etheridge, E.C., Gowans, A.R.D. et al. (2016). Inter and intra-population phenotypic and genotypic structuring in the European whitefish Coregonus lavaretus, a rare freshwater fish in Scotland. Journal of Fish Biology, 88(2), 580-594. https://doi.org/10.1111/jfb.12855

Adams, C.E., Lyle, A.A., Dodd, J.A., Bean, C.W., Winfield, I.J., Gowans, A.R. D. et al. (2014). Translocation as a conservation tool: Case studies from rare freshwater fishes in Scotland. The Glasgow Naturalist, 26(1), $17-24$.

Adams, C.E. \& Maitland, P.S. (1998). The Ruffe population of Loch Lomond, Scotland: Its introduction, population expansion and interaction with native species. Journal of Great Lakes Research, 24(2), 249-262. https://doi.org/10.1016/s0380-1330(98)70817-2

Adams, C.E. \& Tippett, R. (1991). Powan Coregonus lavaretus (L.) ova predation by newly introduced ruffe, Gymnocephalus cernuus (L.) in Loch Lomond, Scotland. Aquaculture and Fisheries Management, 22(2), 239-246. https://doi.org/10.1111/j.1365-2109. 1991.tb00513.x

Brown, E.A.R. \& Scott, D.B.C. (1994). Life histories of the powan, Coregonus lavaretus (L.) (Salmonidae, Coregoninae) of Loch Lomond and Loch Eck. Hydrobiologia, 290(1-3), 121-133. https://doi.org/10.1007/ BF00008959

Chauvenet, A., Ewen, J.G., Armstrong, D., Blackburn, T. \& Pettorelli, N. (2013). Maximizing the success of assisted colonizations. Animal Conservation, 16(2), 161-169. https://doi.org/10.1111/j.1469-1795. 2012.00589.x

Council of the European Communities. (1992). Council Directive 92/43/EEC of 21 May 1992 on the conservation of natural habitats and of wild fauna and flora. Official Journal of the European Communities, L206, 7-50.

Etheridge, E.C., Bean, C.W. \& Adams, C.E. (2011). An experimental approach to estimating vulnerability of European whitefish (Coregonus lavaretus) ova to predation by invasive ruffe (Gymnocephalus cernuus). Ecology of Freshwater Fish, 20(2), 299-307. https://doi.org/10.1111/j. 1600-0633.2011.00496.x

Etheridge, E.C., Bean, C.W., Maitland, P.S. \& Adams, C.E. (2010). Morphological and ecological responses to a conservation translocation of powan (Coregonus lavaretus) in Scotland. Aquatic Conservation: Marine and Freshwater Ecosystems, 20(3), 274-281. https://doi.org/10.1002/aqc.1101

Etheridge, E.C., Bean, C.W., Maitland, P.S., Ballantyne, S. \& Adams, C.E. (2012). Discontinuous infraspecific variation in ecological and morphological traits has consequences for conservation of powan (Coregonus lavaretus) in Scotland. Advances in Limnology, 63, 505-517. https://doi.org/10.1127/advlim/63/2012/505

Excoffier, L. \& Lischer, H. (2010). Arlequin suite ver 3.5: A new series of programs to perform population genetics analyses under Linux and Windows. Molecular Ecology Resources, 10(3), 564-567. https://doi. org/10.1111/j.1755-0998.2010.02847.x

Foll, M. \& Gaggiotti, O. (2008). A genome scan method to identify selected loci appropriate for both dominant and codominant markers: A Bayesian perspective. Genetics, 180(2), 977-993. https://doi.org/10. 1534/genetics.108.092221
Griffith, B., Scott, J.M., Carpenter, J.W. \& Reed, C. (1986). Translocation as a species conservation tool: Status and strategy. Science, 245(4917), 477-480. https://doi.org/10.1126/science.245.4917.477

Guo, S. \& Thompson, E. (1992). Performing the exact test of Hardy-Weinberg proportion for multiple alleles. Biometrics, 48(2), 361-372. https://doi.org/10.2307/2532296

Hagenlund, M., Østbye, K., Langdal, K., Hassve, M., Pettersen, R., Anderson, E. et al. (2015). Fauna crime: Elucidating the potential source and introduction history of European smelt (Osmerus eperlanus L.) into Lake Storsjøen, Norway. Conservation Genetics, 16(5), 1085-1098. https://doi.org/10.1007/s10592-015-0724-2

Hassve, M.H., Hagenlund, M., Østbye, K., Häkli, K., Vogler, T., Gregersen, F. et al. (2020). The spatio-temporal axis for phenotypic change: A comparison of source and translocated Arctic charr populations after 25 generations. BioRxiv, 12(08), 416073. https://doi. org/10.1101/2020.12.08.416073

Hothorn, T., Bretz, F. \& Westfall, P. (2008). Simultaneous inference in general parametric models. Biometrical Journal, 50(3), 346-363. https://doi.org/10.1002/bimj.200810425

Hufford, K.M. \& Mazer, S.J. (2003). Plant ecotypes: Genetic differentiation in the age of ecological restoration. Trends in Ecology \& Evolution, 18(3), 147-155. https://doi.org/10.1016/S0169-5347(03)00002-8

IUCN. (2015). The IUCN Red List of Threatened Species. Version 2015-4. Available at: www.iucnredlist.org [Accessed 1 November 2019]

Joint Nature Conservation Committee. (2007). Report on the species and habitat review (UK BAP). Peterborough.

Kalinowski, S. (2005). HP-RARE 1.0: A computer program for performing rarefaction on measures of allelic richness. Molecular Ecology Notes, 5(1), 187-189. https://doi.org/10.1111/j.1471-8286.2004.00845.x

Koskinen, M.T., Haugen, T.O. \& Primmer, C.R. (2002). Contemporary Fisherian life-history evolution in small salmonid populations. Nature, 419(6909), 826-830. https://doi.org/10.1038/nature01029

Linklater, W.L., Adcock, K., du Preez, P., Swaisgood, R.R., Law, P.R., Knight, M.H. et al. (2011). Guidelines for large herbivore translocation simplified: Black rhinoceros case study. Journal of Applied Ecology, 48(2), 493-502. https://doi.org/10.1111/j.1365-2664.2011.01960.x

Lyle, A.A., Stephen, A. \& Adams, C.E. (2017). Establishment of conservation refuge populations for Scotland's rare freshwater fish, the powan Coregonus lavaretus. The Glasgow Naturalist, 26(3), 3-9.

Maitland, P. \& Lyle, A.A. (2013). Ex situ and in situ approaches, including assisted reproduction, for the conservation of native species of charr (Salmonidae) and whitefish (Coregonidae) in Scotland. International Zoo Yearbook, 47(1), 129-139. https://doi.org/10.1111/j.1748-1090. 2012.00192.x

Maitland, P.S., East, K. \& Morris, K.H. (1983). Ruffe Gymnocephalus cernua, new to Scotland in Loch Lomond. The Scottish Naturalist, 95(1), 7-9.

Maitland, P.S. \& Lyle, A.A. (1991). Conservation of freshwater fish in the British Isles: The current status and biology of threatened species. Aquatic Conservation: Marine and Freshwater Ecosystems, 1(1), 25-54. https://doi.org/10.1002/aqc.3270010104

Müller, H. \& Eriksson, O. (2013). A pragmatic and utilitarian view of species translocation as a tool in conservation biology. Biodiversity and Conservation, 22(8), 1837-1841. https://doi.org/10.1007/s10531013-0504-6

Østbye, K., Amundsen, P.A., Bernatchez, L., Klemetsen, A., Knudsen, R., Kristoffersen, R. et al. (2006). Parallel evolution of ecomorphological traits in the European whitefish Coregonus lavaretus (L.) species complex during postglacial times. Molecular Ecology, 15(13), 3983-4001. https://doi.org/10.1111/j.1365-294x.2006.03062.x

Patton, J.C., Gallaway, B., Fechhelm, R. \& Cronin, M. (1997). Genetic variation of microsatellite and mitochondrial DNA markers in broad whitefish (Coregonus nasus) in the Colville and Sagavanirktok rivers in northern Alaska. Canadian Journal of Fisheries and Aquatic Sciences, 54(7), 1548-1556. https://doi.org/10.1139/cjfas-54-7-1548 
Peakall, R. \& Smouse, P. (2006). GENALEX 6: Genetic analysis in Excel. Population genetic software for teaching and research. Molecular Ecology Notes, 6(1), 288-295. https://doi.org/10.1111/j.1471-8286. 2005.01155.x

Præbel, K., Couton, M., Knudsen, R. \& Amundsen, P.-A. (2016). Genetic consequences of allopatric and sympatric divergence in Arctic charr (Salvelinus alpinus (L.)) from Fjellfrøsvatn as inferred by microsatellite markers. Hydrobiologia, 783(1), 257-267. https://doi.org/10.1007/ s10750-016-2648-3

Præbel, K., Gjelland, K.Ø., Salonen, E. \& Amundsen, P.A. (2013). Invasion genetics of vendace (Coregonus albula (L.)) in the Inari-Pasvik watercourse: Revealing the origin and expansion pattern of a rapid colonization event. Ecology and Evolution, 3(5), 1400-1412. https:// doi.org/10.1002/ece3.552

Præbel, K., Westgaard, J., Amundsen, P., Siwertsson, A., Knudsen, R., Kahilainen, K. et al. (2013). A diagnostic tool for efficient analysis of the population structure, hybridization and conservation status of European whitefish (Coregonus lavaretus (L.)) and vendace (C. albula (L.)). Advances in Limnology, 64, 247-255. https://doi.org/10.1127/ 1612-166x/2013/0064-0026

R Core Team. (2017). R: A language and environment for statistical computing. Vienna: R Foundation for Statistical Computing.

Ricciardi, A. \& Simberloff, D. (2009). Assisted colonization is not a viable conservation strategy. Trends in Ecology \& Evolution, 24(5), 248-253. https://doi.org/10.1016/j.tree.2008.12.006

Rice, T., Schork, N. \& Rao, D. (2008). Methods for handling multiple testing. In: D. Rao, C. Gu (Eds.) Genetic dissection of complex traits. San Diego, CA: Elsivier, pp. 293-308.

Rogers, S.M., Marchand, M. \& Bernatchez, L. (2004). Isolation, characterization and cross-salmonid amplification of 31 microsatellite loci in the lake whitefish (Coregonus clupeaformis, Mitchill). Molecular Ecology Notes, 4(1), 89-92. https://doi.org/10.1046/j.1471-8286. 2003.00578.x

Rousset, F. (2007). Genepop 007: A complete reimplementation of the Genepop software for Windows and Linux. Molecular Ecology Resources, 8(1), 103-106. https://doi.org/10.1111/j.1471-8286.2007. 01931.x

Salminen, M., Koljonen, M.L., Säisä, M. \& Ruuhijärvi, J. (2012). Genetic effects of supportive stockings on native pikeperch populations in boreal lakes - Three cases, three different outcomes. Hereditas, 149(1), 1-15. https://doi.org/10.1111/j.1601-5223.2011.02230.x

Siwertsson, A., Knudsen, R., Adams, C.E., Præbel, K. \& Amundsen, P.A. (2013). Parallel and non-parallel morphological divergence among foraging specialists in European whitefish (Coregonus lavaretus). Ecology and Evolution, 3(6), 1590-1602. https://doi.org/10.1002/ ece3.562

Stockwell, C.A., Hendry, A.P. \& Kinnison, M.T. (2003). Contemporary evolution meets conservation biology. Trends in Ecology \& Evolution, 18(2), 94-101. https://doi.org/10.1016/S0169-5347(02)00044-7

Stockwell, C.A., Mulvey, M. \& Vinyard, G.L. (1996). Translocations and the preservation of allelic diversity. Conservation Biology, 10(4), 1133-1141. https://doi.org/10.1046/j.1523-1739.1996.10041133.x

Storfer, A. (1999). Gene flow and endangered species translocations: A topic revisited. Biological Conservation, 87(2), 173-180. https://doi. org/10.1016/s0006-3207(98)00066-4

Susnik, S., Snoj, A. \& Dovc, P. (1999). Microsatellites in grayling (Thymallus thymallus): Comparison of two geographically remote populations from the Danubian and Adriatic river basin in Slovenia. Molecular Ecology, 8(10), 1756-1758. https://doi.org/10.1046/j.1365-294x. 1999.00723-2.x

Szpiech, Z., Jakobsson, M. \& Rosenberg, N. (2008). ADZE: A rarefaction approach for counting alleles private to combinations of populations. Bioinformatics, 24(21), 2498-2504. https://doi.org/10.1093/ bioinformatics/btn478
Tallmon, D., Koyuk, A., Luikart, G. \& Beaumont, M. (2008). ONeSAMP: A program to estimate effective population size using approximate Bayesian computation. Molecular Ecology Resources, 8(2), 299-301. https://doi.org/10.1111/j.1471-8286.2007.01997.x

Taylor, S.S. \& Jamieson, I.G. (2008). No evidence for loss of genetic variation following sequential translocations in extant populations of a genetically depauperate species. Molecular Ecology, 17(2), 545-556. https://doi.org/10.1111/j.1365-294X.2007.03591.x

Thrimawithana, A., Ortiz-Catedral, L., Rodrigo, A. \& Hauber, M.E. (2013). Reduced total genetic diversity following translocations? A metapopulation approach. Conservation Genetics, 14(5), 1043-1055. https://doi.org/10.1007/s10592-013-0494-7

Turgeon, J., Estoup, A. \& Bernatchez, L. (1999). Species flock in the North American Great Lakes: Molecular ecology of Lake Nipigon ciscoes (Teleostei: Coregonidae: Coregonus). Evolution, 53(6), 1857-1871. https://doi.org/10.2307/2640446

Van Andel, J. (1998). Intraspecific variability in the context of ecological restoration projects. Perspectives in Plant Ecology and Evolution, 1(2), 221-237. https://doi.org/10.1078/1433-8319-00060

Van Oosterhout, C., Hutchinson, W., Wills, D. \& Shipley, P. (2004). MICRO-CHECKER: Software for identifying and correcting genotyping errors in microsatellite data. Molecular Ecology Notes, 4(3), 535-538. https://doi.org/10.1111/j.1471-8286.2004.00684.x

Vitalis, R., Dawson, K., Boursot, O. \& Belkhir, K. (2003). DetSel 1.0: A computer program to detect markers responding to selection. Journal of Heredity, 94(5), 429-431. https://doi.org/10.1093/jhered/esg083

Weeks, A.R., Sgro, C.M., Young, A.G., Frankham, R., Mitchell, N.J., Miller, K.A. et al. (2011). Assessing the benefits and risks of translocations in changing environments: A genetic perspective. Evolutionary Applications, 4(6), 709-725. https://doi.org/10.1111/j. 1752-4571.2011.00192.x

Weir, W. \& Cockerham, C. (1984). Estimating F-statistics for the analysis of population-structure. Evolution, 38(6), 1358-1370. https://doi.org/ 10.1111/j.1558-5646.1984.tb05657.x

Winfield, I.J., Bean, C.W., Gorst, J., Gowans, A.R.D., Robinson, M. \& Thomas, R. (2013). Assessment and conservation of whitefish (Coregonus lavaretus (L.)) in the UK. Advances in Limnology, 64, 305-321. https://doi.org/10.1127/1612-166X/2013/0064-0023

Winkler, K.A. \& Weiss, S. (2008). Eighteen new tetranucleotide microsatellite DNA markers for Coregonus lavaretus cloned from an alpine lake population. Molecular Ecology Resources, 8(5), 1055-1058. https://doi.org/10.1111/j.1755-0998.2008.02153.x

Wright, D.J., Spurgin, L.G., Collar, N.J., Komdeur, J., Burke, T. \& Richardson, D.S. (2014). The impact of translocations on neutral and functional genetic diversity within and among populations of the Seychelles warbler. Molecular Ecology, 23(9), 2165-2177. https://doi. $\operatorname{org} / 10.1111 /$ mec.12740

\section{SUPPORTING INFORMATION}

Additional supporting information may be found online in the Supporting Information section at the end of this article.

How to cite this article: Præbel, K., Bean, C.W., Dodd, J.A., Etheridge, E.C., Gowans, A.R.D., Knudsen, R. et al. (2021). Allelic losses and gains during translocations of a high conservation value fish, Coregonus lavaretus. Aquatic Conservation: Marine and Freshwater Ecosystems, 1-11. https://doi.org/10.1002/aqc.3623 